\title{
El papel de Granada en las relaciones castellano-portuguesas (1369-1492)
}

\author{
Jose Enrique López de Coca Castañer \\ Universidad de Málaga
}

\section{RESUMEN ABSTRACT}

Temor de Castilla a una alianza entre

Portugal y la Granada musulmana. La casa de Avis aspira a tomar parte en la conquista del emirato nazari. Papel que desempeña el infante don Enrique en todo esto. Castellanos y portugueses colaboran en la defensa de Ceuta y otras plazas fuertes contra los ataques de granadinos y marroquies.

\section{PALABRAS CLAVE \\ Granada. Portugal. Castilla. \\ KEY WORDS \\ Granada. Portugal. Castile.}

Fear of Castile to an alliance between Portugal and Moslem Granada. The House of Avis long for taking part in the conquest of the Nasri kingdom. The role of prince $D$. Enrique in this business. Castilians and Portuguese collaborate in the defence of Ceuta and other strongholds against the attacks of natives of Granada and Moroccans.

Llevo algún tiempo estudiando las relaciones entre Portugal y el reino nazarí de Granada, antes y después de la conquista de Ceuta en 1415. He dedicado una atención especial a las pretensiones portuguesas de intervenir en el territorio granadino pese a que la Corona de Castilla lo consideraba como una especie de coto privado. También me he ocupado de averiguar cual fue la contribución lusitana a la conquista del emirato por los Reyes Católicos '.

La relación de trabajos es la que sigue: "Portugal y Granada: presencia lusitana en la conquista y repoblación del reino Granadino (siglos Xv-xvi)", en Actas das II Jornadas Luso-Espanholas de Història Medieval, Il(Oporto, 1987), pp. 737-757; “Granada y la expansión portuguesa en el Magreb Extremo». Historia. Instituciones. Documentos n. 25 (1998), 351-367; "Portugal y los derechos castellanos sobre Granada(siglo xv)», Homenatge al Dr. Manuel Riu i Riu. Acta Historica et Archaeologica Mediaevalia n." 
En esta ocasión quiero insistir en el papel desempeñado por Granada en las relaciones luso-castellanas a partir del advenimiento de los Trastámaras. Las páginas que siguen son una sintesis elaborada con datos y reflexiones extraídas de la investigación anterior. Por eso, citaré a pie de página sólo aquellos trabajos que no pude consultar en su momento, o que aportan alguna novedad a lo ya dicho.

\section{$1369-1415$}

Tras la muerte de Pedro I en los campos de Montiel (23 de marzo de 1369) su vasallo Muhammad V, emir de Granada, se negó a renovar las treguas con Enrique de Trastámara. Acto seguido, el nazari entraba en tratos con el rey Fernando I de Portugal, que habia reivindicado el trono castellano al ver que el príncipe Enrique no contaba con el apoyo unánime de la nobleza. Aquella misma primavera el monarca portugués y el emir granadino suscribian una alianza militar en contra de Castilla "por tempo assinado de cinquoenta años", según refiere el cronista Fernão Lopes. Mientras que el portugués invadía Galicia en julio de 1369, el nazarí reunia a su gente y marchaba sobre la ciudad de Algeciras, de la que se apoderaba a fines de ese mismo mes. Y para ayudar a los seguidores del difunto don Pedro, que se habian encerrado en Carmona, Muhammad $V$ hará algunas incursiones en los alrededores de Sevilla en el mes de octubre, atacando y saqueando las plazas de Osuna y Marchena.

La alianza luso-granadina no iría más lejos, pues en mayo de 1370 el emir firmaba una tregua de ocho años con los castellanos. Fue el resultado, al parecer, de una iniciativa del famoso visir e intelectual lbn al-Jatíb, quien logró además que los granadinos dejaran de pagar tributo a Castilla durante algún tiempo. Este acuerdo trajo un enfriamiento de las relaciones con Portugal que daría paso, posteriormente, a la ruptura entre ambos estados. En 1374, Fernando I se consideraba en guerra con el emir de Granada porque éste le habia tomado unos navíos con sus gentes y haberes.

Una década más tarde, sin embargo, Castilla volverá a sentirse amenazada por el fantasma de una alianza entre sus vecinos con motivo de la guerra contra Portugal de 1383-1387. No hay noticias sobre un posible entendimiento entre granadinos y portugueses antes de la derrota de Juan I de Castilla en Aljubarrota(1385). Pero la propaganda castellana insistirá en lo contrario a partir de la intervención de Juan de Gante en el conflicto. En las cortes de Segovia celebradas en 1386, Juan I censuraba al duque de Lancaster porque, según le habian informado, andaba negociando con los granadinos la cesión de una parte del reino a cambio de ayuda para derrotar a su rival. Una acusación explicable porque el monarca castellano no las tenía todas consigo respecto a la actitud que podía adoptar el nazari en aquellos momentos.

22(1999-2001), 601-616; "Sobre las relaciones de Portugal con el reino de Granada(1369-1415)», Meridies. Revista de Historia Medieval V-VI(2002), 205-210. 
Finalmente, Granada se mantuvo al margen de la guerra entre castellanos y portugueses. Años después, los emires pretenderán que Castilla les recompense por su neutralidad eximiéndoles de la obligación de prestar vasallaje. Como declara un embajador moro en 1410, «no hera razon en tienpo de holgura ser mal tratados los que cunplieron con ellos en el tienpo de las sus nesçesidades e no quisieron fazer ligas ni ser contra ellos con sus contrarios". Mucho más explícita va a mostrarse la diplomacia nazari cuando Castilla exija de nuevo la vinculación feudal en 1439. Don Iñigo López de Mendoza, portavoz castellano en las negociaciones, recibia entonces la siguiente respuesta: “(...)que vean lo que havía en Castilla antes de oy entre los señores pasados e ensalçados, el rey don lohan e el rey don Enrique con los ingleses e Portugal, del ruido e la guerra e peleas e lo que fisieron los señores reyes de Granada: las villas çercanas a los moros fueron bien guardadas, e nunca fue oydo ruego de rey ninguno por amor dellos, e bien que por otros reyes eran rogados que fuesen contrarios al rey de Castilla(...)». Pero no está claro si los anglo-portugueses solicitaron ayuda a los granadinos en aquellos años cruciales o, por el contrario, fue Granada la que se ofreció a participar en la guerra de independencia lusa según afirma el cronista Gomes Eanes de Zurara, el cual añade que Juan I rechazó tan ventajosa propuesta porque no quería aliarse con los enemigos de la fe.

El comercio entre Portugal y el emirato granadino-que viene de antiguo-se intensificará posteriormente por lo que dan a entender las declaraciones de unos emisarios nazaries que fueron a Lisboa en 1414. Es significativo, en este sentido, que a fines del Trescientos hubiera una "posada de los portugueses" en la misma ciudad de Granada. Por regla general, los establecimientos de este tipo solian abrirse en las ciudades portuarias de un país islámico, pero no en las del interior. El hecho de que los comerciantes lusitanos dispusieran de un fondaco en la capital nazarí indica que gozaban del favor de los emires ${ }^{2}$.

Sin embargo, la casa de Avis jamás disimuló la animadversión que sentía por el Islam. Recordemos que el advenimiento de la nueva dinastía se produjo tras una guerra con Castilla que fue, al mismo tiempo, una guerra civil. La expansión exterior pareció entonces necesaria para dar empleo a una nobleza turbulenta, poniéndola al servicio de la monarquia al ofrecerle posibilidades de enriquecimiento rápido. Pero habia que escoger entre el escenario magrebí y el granadino. Y lo que es más importante, asegurarse la benevolencia castellana en el segundo caso.

Fueron los Trastámaras quienes, en cierto modo, tomaron la iniciativa al invitar a sus vecinos a participar en la guerra granadina en el transcurso del largo proceso negociador que condujo a la paz de Ayllon. En 1399 Enrique III pedía ayuda naval por tres años, sin coste para él, como descargo de las culpas en que habian incurrido los portugueses al combatir contra los cristianos de Castilla. Durante la regencia conjunta de Catalina de Lancaster y su cuñado Fernando, la diplomacia

2 Pero no se conservan documentos de ninguna de las partes que den fe de la importancia de ese comercio. Felipe Themudo Barata, que se ha ocupado del tema, da cuenta solamente de las exportaciones de miel a Málaga hechas por un judio de Setúbal circa 1400. Cf. Navegação, Comércio e Relações políticas: os portugueses no Mediterráneo Occidental(1385-1466), Coimbra, 1998.p. 80. 
castellana irá más lejos al pretender que el monarca lusitano acuda al llamamiento del rey de Castilla cada vez que éste salga a combatir a los infieles. Si los motivos familiares impulsaban a doña Catalina a buscar un acercamiento-era hermana de la reina de Portugal-, el infante don Fernando, ocupado en una ofensiva general contra los musulmanes que culminaría en la toma de Antequera(1410), porfiaba porque la obligación portuguesa de ayudar a la conquista de Granada figurase en el futuro tratado. Portugal rechazó esta exigencia para no reconocer la soberania castellana sobre el país. Por el tratado de Ayllon (31 de octubre de 1411) Castilla abandonaba los sueños hegemónicos: ninguna de sus cláusulas menciona la ayuda militar lusitana hasta entonces pedida con insistencia.

No obstante, a poco de firmarse la paz la regente solicitaba el envio de diez o doce galeras para el primer verano en que se hiciera la guerra a los granadinos, a lo que responde complacido el monarca portugués. Según Luis Felipe Thomaz, que sigue al cronista Fernão Lopes, la demanda no pasaba de ser un sondeo sobre las intenciones lusitanas, pero Juan I contestó de buena gana pues el tratado de paz, válido hasta que el heredero castellano alcanzara la mayoría de edad en 1420 , hacía posible el proyecto de combatir contra los musulmanes de Granada o del Magreb. En cambio, Luis Suárez Fernández, que se apoya en Zurara, atribuye a Juan I la iniciativa de combatir a los granadinos. Éste se lo comunica al infante don Fernando ya que, por tradición, Castilla consideraba al emirato nazari como su área de influencia. Pero el príncipe Trastámara, ocupado ahora en su candidatura al trono aragonés-al que accederá por el compromiso de Caspe(15 de junio de 1412) - responde que habia firmado treguas con Granada por algún tiempo.

Ambos cronistas escriben con posterioridad a los hechos que narran. Pero si Lopes trabaja con documentos escritos-aunque se considera que no es seguro a partir de 1390-, Zurara se basa en los testimonios orales de los infantes don $\mathrm{Pe}$ dro y don Enrique, hijos de Juan I. Con todo, es posible que no haya discrepancia entre las dos versiones: simplemente la carta de doña Catalina daría pie a que el portugués pidiera permiso a don Fernando, que era el que disponía de más medios para hacer la guerra. Será sólo ante el desinterés del castellano cuando surja la idea de atacar la ciudad de Ceuta, en la orilla meridional del estrecho de Gibraltar.

\section{5-1437}

Cuando los portugueses se apoderan de Ceuta el 21 de agosto de 1415, la ciudad ya no era el emporio de antaño y proporcionó menos botín del que se esperaba. Pero en vez de destruirla y abandonarla, Juan I optó por conservarla con vistas a jugar un papel influyente en la zona ${ }^{3}$. El 20 de octubre de aquel año enviaba una carta a Fernando I de Aragón, proponiéndole la conquista del territorio grana-

3 También hay que tener en cuenta la credibilidad internacional que logró la monarquia portuguesa con esta victoria. Barata, F. T.: ob. cit., p. 401. 
dino con la colaboración de Castilla. Se ha observado que éste tardó cinco meses en contestar porque debía consultarlo primero con su cuñada. Pero hay razones para pensar que don Fernando habia decidido reanudar las hostilidades contra los moros por la fecha en que recibió la propuesta portuguesa. Tanto Fernão Lopes como Zurara aseguran que el rey de Aragón la acogió con entusiasmo, si bien no pudo secundar la invitación al sobrevenirle la muerte. El primero de los cronistas añade que Juan I hizo el mismo requerimiento a Catalina de Lancaster, que se excusó alegando su condición de mujer y madre de un hijo de pocos años.

El deceso de la reina regente en 1418 impidió que se confirmara la paz entre Castilla y Portugal, que expiraba dos años después. Nuevos factores van a estorbar ahora las relaciones-por otra parte pacíficas-entre ambas monarquías ${ }^{4}$. $\mathrm{Si}$ Alfonso el Magnánimo, hijo de Fernando I, ocupaba el trono aragonés desde 1416, sus hermanos Pedro, Juan y Enrique seguian viviendo en Castilla, donde contaban con extensas posesiones en Extremadura y otras partes. Dirigentes de un partido nobiliario que no quería el gobierno efectivo de Juan II y su valido $D$. Álvaro de Luna, los mal llamados Infantes de Aragón no tardaron en hacer gestos hostiles a los portugueses.

Mientras tanto, Ceuta se habia convertido en un importante foco de actividad corsaria bajo el mandato de su primer gobernador, el conde D. Pedro de Meneses. Los marinos portugueses perseguian a los cárabos y fustas que iban y venían entre Málaga y los puertos marroquíes de Badis, Tánger y Anfa(Casablanca), amenazando con estrangular las comunicaciones marítimas del emirato granadino. $Y$ no contentos con esto, van a tomar la costumbre de echar partidas en tierra para capturar gente y ganado, tanto en el litoral de Marruecos como en el de Granada. No es de extrañar, pues, que los nazaries intenten expulsarlos de Ceuta cuanto antes.

El emir Muhammad IX el Izquierdo puso cerco a la plaza en agosto de 1419 con ayuda norteafricana. El plan de acción consistía en establecer una cabeza de puente en Almina, hoy Monte Hacho, mientras los contingentes reclutados por los jefes tribales del norte de Marruecos atacaban Ceuta desde el interior. $Y$ así se hizo. Pero los magrebies no combatieron con el entusiasmo que cabía esperar y la pronta llegada de una flota de socorro al mando del infante don Enrique sembró el pánico entre los marinos granadinos, que abandonaron a su suerte a la gente desembarcada mientras ellos buscaban refugio en la bahía de Gibraltar. En Almina se perdieron tres mil hombres entre muertos, heridos y desaparecidos, contándose entre los primeros un sobrino del emir ${ }^{5}$.

"Lo que no impedirá que en 1419 navios portugueses y vizcainos se vean envueltos en un serio incidente en el puerto de Cádiz: según un fragmento poco conocido de la Crónica de Juan II, de Alvar García de Santamaria, los portugueses desembarcaron con la intención de saquear la ciudad. Lo refiere LADeRo Quesada, M. A.: "Portugueses en la frontera de Granada», En la España Medieval 23 (2000), 88.

De la lectura de Zurara se desprende que los granadinos atacaron a Ceuta una sola vez, en el verano de 1419. Hay autores, sin embargo, que sostienen que hubo dos cercos, en 1418 y 1419 respectivamente. Sobre esta cuestión, véase Mendes Drumond Braga, I. y Drumond Braga, P.: Ceuta portuguesa (1415-1656) Ceuta, 1998.pp. 33-35. 
La ocasión era propicia para que Juan I recuperara la iniciativa militar en África del Norte. Pero, inseguro a causa de la situación política en la Península, no se decide. $Y$ en 1421 su hijo don Enrique, gobernador del Algarbe, empieza a despachar barcos hacia el sur, a reconocer la costa africana, con la esperanza de alcanzar la Etiopia cristiana y, de este modo, amenazar al Magreb en su retaguardia.

La monarquía portuguesa quiso resolver el litigio entre los Infantes de Aragón y la corona castellana. Un primer paso, de consecuencias peligrosas, fue la boda del heredero luso Duarte con Leonor, hermana de los Infantes, en 1428. A partir del año siguiente los infantes Pedro y Enrique de Aragón iniciaban sus correrías por Extremadura, confiados en que aquella les apoyaria desde el otro lado de la frontera. El segundo será la mediación del infante don Pedro de Portugal ante Alfonso el Magnánimo y la firma de la tregua de Majano el 16 de julio de 1430, que prohibia a los infantes aragoneses residir en Castilla.

Agradecido, don Álvaro de Luna aceptaba la paz perpetua que Juan I le propondría acto seguido, firmándose los capítulos correspondientes en Medina del Campo el 30 de octubre de 1431. En esa fecha el rey de Castilla había reanudado la guerra contra Granada con el propósito de reverdecer los laureles obtenidos por su tío Fernando. Los portugueses manifestaron su deseo de tomar parte en la misma y Juan II va a acceder en un momento determinado.

Los infantes Enrique y Pedro de Aragón habían rechazado los términos acordados en Majano y continuaban resistiendo en sus castillos de Extremadura. Tenían a su favor la ambigüedad y dudas del maestre de Alcántara, don Juan de Sotomayor, vinculado de antiguo a la casa de los Infantes, pero obligado al mismo tiempo a mantener la obediencia al rey. A tenor de lo que dicen algunas crónicas castellanas, el infante don Enrique de Portugal se prestó a garantizar un acuerdo entre el susodicho maestre y el rey de Castilla en mayo de 1432.

La mediación no era desinteresada. La paz perpetua abría nuevas expectativas a la expansión lusitana en Marruecos, o en Granada. Y don Enrique había tratado de obtener licencia de su padre para organizar una armada contra los musulmanes de una $u$ otra orilla del Estrecho. Esto parece haber disgustado en principio al heredero de la corona don Duarte, que trató confidencialmente el asunto con sus hermanos el infante don Juan y el conde de Barcelos(Alfonso, bastardo de Juan 1) y los hijos de éste, los condes de Ourém y de Arraiolos. El texto de la consulta debió variar en cada caso por lo que se deduce de las respuestas que $D$. Duarte recibió por escrito a lo largo de la primavera de 1432.

El conde de Barcelos se opone a la intervención en Granada y manifiesta sus reservas respecto a la conveniencia de luchar en Marruecos a la vista de lo que estaba costando mantener Ceuta. Coincide hasta cierto punto con el parecer de su medio hermano el infante $\mathrm{D}$. Juan, para quien la única guerra posible era la de África, ya que contra Granada no se podria combatir sin permiso del rey de Castilla "por ser sua conquista". El conde de Ourém, respondiendo a si se debe- 
ría participar en la guerra contra Granada que había emprendido Juan II, opina que podria hacerse por tierra o mar indistintamente, a condición de que se entregaran al castellano todas las plazas que se ganaran; en cuanto a Marruecos, recomienda que sea don Enrique quien intente dar a sus expensas un golpe de mano sobre Tánger o Arcila.

Pero es la opinión del conde de Arraiolos, cronológicamente la primera de las formuladas (21 de abril de 1432), la que nos interesa más directamente. Habiale preguntado D. Duarte si convenía que el infante don Enrique aceptara la amistosa composición que le habían ofrecido el rey de Castilla y el maestre de Alcántara "com çertas condiçoes". Aunque se desconocen los términos exactos de las mismas, parece que estaban relacionados con una invitación a participar en la guerra granadina. Según el conde, Juan II hacía esto porque deseaba neutralizar a los Infantes de Aragón con la ayuda del maestre de Alcántara; de lo contrario, el infante $D$. Enrique de Avis nada tendría que hacer en Castilla. $Y$ añade que si éste aceptaba el mentado acuerdo, podría llegar a enseñorearse de Granada, intervenir directamente en la política del reino vecino y obtener para Portugal las islas Canarias, objeto de disputa en aquel entonces.

El proyecto se iria al traste después que don Juan de Sotomayor cambiara de opinión y cometiese un delito de felonía al entregar Alcántara a los infantes de Aragón a fines de junio de aquel año. Aunque a los pocos días la situación daba un nuevo vuelco al producirse el secuestro del infante don Pedro de Aragón por Gutierre de Sotomayor, sobrino del maestre, clavero de la orden de Alcántara y afecto al rey.

No voy a detenerme en comentar las gestiones hechas por D. Duarte y por su padre, el rey de Portugal, para obtener la liberación del infante prisionero. Baste con recordar que éste recuperó la libertad después que su hermano Enrique entregara a Juan II todas las fortalezas que ambos poseían en el reino de Castilla. Luego pasaron a Portugal y, en mayo de 1433, viajaban por mar hasta Valencia ${ }^{6}$.

En el desarrollo de estas negociaciones jugó un papel relevante el embajador portugués Pero Gonzales de Malfaia que, en julio de 1432, llegaba a Salamanca con el siguiente mensaje de Juan I para su homónimo castellano: “(...) que el le vernia ayudar para la sua conquista de Granada, con su cuerpo e con sus fijos e a sua costa". Fue el último e infructuoso intento del monarca luso. Su hijo Duarte, que le sucederá en agosto de 1433, tampoco tuvo mejor suerte cuando, en la primavera del año siguiente, ofrecía a Castilla su colaboración para la guerra granadina. En lo sucesivo no le quedará otro remedio que apoyar a su hermano Enrique en su proyecto de guerrear contra Marruecos.

La marcha de los infantes aragoneses tuvo una secuela inesperada en lo que toca al emirato nazari. Alfonso $V$ de Aragón propondrá al rey de Castilla la cesión al infante $D$. Enrique de cualquier derecho que tenga a la conquista de Granada, a cambio de que éste renuncie a todas sus posesiones en tierras castellanas. Ver el memorial de instrucciones firmado en Palermo, ei 30 de septiembre de 1433, que publica Salichu I LLUCH, R.: Documents per a la historia de Granada del regnat d'Alfons el Magnánim(1416-1458). Barcelona, 1999. Doc. 279. 
Las repetidas negativas castellanas se explican por el temor a que los portugueses aprovecharan su intervención en la guerra de Granada para quedarse con el puerto de Gibraltar. El cerco de 1419 puso de manifiesto que convenía ocupar el Peñón para proteger a Ceuta de un nuevo ataque granadino. Sólo las adversas condiciones climáticas y marítimas-proximidad del invierno y fuerza de las corrientes del Estrecho-impidieron que el infante don Enrique intentara tomar Gibraltar según refiere Gomes Eanes de Zurara. Este cronista da cuenta, además, del malestar generado por el proyecto entre los consejeros del Infante, que consideraban esta plaza como «lugar da conquista de Castella». No cabe duda de que la ocupación del Peñón por los portugueses habría sido contemplada como una intromisión en el área de influencia castellana. El temor a que esto sucediera explica que en 1420 dos famosos fronteros andaluces, los hermanos Juan y Gonzalo de Saavedra, recibiesen órdenes de armar unos barcos en Cádiz para atacar Gibraltar si fuera necesario.

Los rumores sobre una intervención portuguesa en la orilla septentrional del Estrecho cobrarian nueva fuerza en los años treinta, coincidiendo con la reanudación de las hostilidades entre Castilla y Granada. Las ofertas de colaboración lusitanas hechas por Juan I, don Enrique y don Duarte contribuyeron a ello. El 27 de julio de 1435 el concejo de Jerez enviaba una carta al capitán mayor de la frontera, residente en Écija, dándole cuenta de la supuesta presencia de navios lusitanos frente al Peñón, «al que conbatian resiamente».R. Sánchez Saus, que ha dado a conocer este documento, plantea la posibilidad de que tales rumores fueran la causa del precipitado ataque de don Juan de Guzmán, conde de Niebla, a Gibraltar en el verano de 1436, que le costó la vida.

\section{$1437-1455$}

El asedio de Tánger en el verano de 1437 fue una bonita oportunidad para que los granadinos se solidarizaran con sus correligionarios norteafricanos. Cuenta Rui de Pina que entre los defensores de la ciudad había un nutrido contingente de ballesteros venidos del otro lado del mar, los cuales contribuirán con su valor y destreza a mantener a raya a los atacantes. Los portugueses son derrotados tras la llegada de una fuerza de socorro al mando de Abú Zakariya, regente de Fez. Éste va a permitirles reembarcar una vez que le prometen devolver Ceuta. Como garantía del trato, retendrá en su poder al infante don Fernando, uno de los jefes de la malhadada expedición.

Pero ni el rey Duarte ni el infante don Enrique estaban dispuestos a cumplir lo pactado. En las cortes celebradas en Leiria propusieron pagar un rescate en dinero $\mathrm{o}$, en su defecto, canjear al príncipe prisionero por todos los cautivos muslimes que hubiera en la Península, sirviéndose del emir de Granada como intermediario y garante. En junio de 1438 llegaba a Fez una embajada nazarí con la oferta de cautivos, que sería despedida por el Abú Zakariya diciendo que no liberaría al infante si no le entregaban Ceuta. La muerte de don Duarte en septiembre de ese mismo 
año, y la crisis que sigue, interrumpieron las conversaciones durante algún tiempo. Cuando se reanuden, en 1441, los portugueses seguirán mostrándose reacios a devolver Ceuta. De ahí que el emir de Granada acabe retirándose de las negociaciones, que concluyen sin resultados. El infante don Fernando morirá dos años después, en una cárcel de Fez.

La negativa a entregar Ceuta parece indicar que África del Norte ha desplazado al emirato granadino en los sueños expansionistas de ciertos sectores de la clase dirigente lusitana. No habrá más ofertas de colaboración a Castilla durante la regencia del infante don Pedro, duque de Coimbra (1438-1448), pese a las buenas relaciones que éste sostenía con don Álvaro de Luna. A lo sumo, participación individual y aislada de algún que otro caballero portugués en las luchas fronterizas entre andaluces y granadinos: en 1444 el joven Duarte de Meneses, bastardo del gobernador de Ceuta, obtuvo licencia de Juan II para servir en la frontera de Granada. En esa fecha, los descubrimientos portugueses al sur del cabo Bojador - que Gil Eanes doblara en 1434-se habian convertido en un objetivo por si mismos. Es significativo que muchos veteranos del corso en aguas mediterráneas participen ahora en la navegación a Guinea. Como Gonzalo de Sintra, que moría en 1444 a manos de los indígenas de Gambia, o Alvaro de Freitas, que zarpaba de Lagos al año siguiente rumbo al sur.

Nadie se interesaba ya por Granada y, sin embargo, es ahora cuando, de parte portuguesa se discuten los derechos castellanos sobre el emirato de una forma explícita y contundente. Con esto me refiero al conselho que el infante don Enrique dio a su sobrino Alfonso $V$ en fecha indeterminada pero próxima, sin duda, a 1448 , año en el que el segundo alcanzó su mayoría de edad. Preguntado si el nuevo monarca debia emprender grandes aventuras en el exterior, tales como la guerra contra los enemigos de la fe cristiana, don Enrique responderá afirmativamente. Y a la cuestión de donde podría desarrollarse esa guerra, contestará que en cualquier parte donde se obtenga fruto, pues las tierras de infieles están a disposición de aquél que las quiera someter, sin que nadie pueda reservárselas a manera de coto. $Y$ agrega:

“(...)que çerto he que, empero que el rrei de Castella diga que Malaga he de sua conquista, se os de Malaga poderem tomar hũu lugãr de Portugal, que o tomariam com leda vontade: $E$ nom o leixariam de fazer por el rrej de Castella dizer que ssom elles de sua conquista. Pois, que mais direitos podem elles teer contra nos que nos moor tenhamos contra eles? ".

No resulta fácil explicar estas declaraciones. Hay que tener en cuenta que a mediados de siglo, coincidiendo con el final de la regencia del duque de Coimbra y su trágica muerte en Alfarrobeira, se multiplicaron los incidentes entre castellanos y portugueses en aguas atlánticas, que a punto estuvieron de conducir a la guerra entre las dos monarquías. En 1450 la rivalidad se extendió a Granada, donde los portugueses de Ceuta van a combatir contra el príncipe Ismail, protegido de Castilla, que se había alzado en armas contra Muhammad IX. Lo más probable es que la re- 
ferencia a Málaga no pase de ser un alarde retórico en boca de alguien como el infante don Enrique, cuyo espíritu aventurero e inconformista era temido por todos. Pero, como se verá luego, algunos historiadores portugueses contemporáneos han interpretado el conselho enriqueño como la manifestación de un deseo más hondo: el de poseer un puerto considerado como la llave del comercio con África.

\section{$1455-1474$}

El 20 de mayo de 1455 Enrique IV, rey de Castilla desde el año anterior, contraia matrimonio, en segundas nupcias, con la infanta Juana, hermano de Alfonso $\checkmark$ de Portugal. La nueva etapa de entendimiento entre los dos reinos hará que cesen las disputas en el Atlántico, donde habrá un reparto tácito de áreas de influencia hasta el tratado de Alcáçovas(1479). En lo que toca al enemigo islámico, mientras que el monarca castellano reanudaba la guerra contra Granada al atacar repetidas veces la zona occidental del emirato, Alfonso $V$ conquistaba Alcazarseguer el 3 de octubre de 1458.

La reacción musulmana no se hizo esperar: la plaza se vio sometida a un primer asedio por el sultán de Fez, de mediados de noviembre de 1458 a comienzos del año siguiente, en el que tomaron parte ballesteros enviados desde Granada. El 2 de julio de 1459 volvía el sultán para un segundo asedio, retirándose el 24 de agosto. Ninguna fuente dice que Ceuta y Alcazarseguer fueran esta vez objeto de un cerco simultáneo. Pero el despliegue de fuerzas hecho por los marroquies hizo temer esa posibilidad en su momento. Lo pone de manifiesto una carta que el conde de Villarreal, gobernador del presidio, enviaba al alcaide de Tarifa en demanda de auxilio. En ella menciona la venida de ballesteros granadinos en número acaso exagerado, y advierte sobre la presencia de galeras tunecinas en el puerto de Badis, unos 150 $\mathrm{km}$ al este de Ceuta. Se trataba de una falsa alarma. Pero la carta que Tarifa remite al concejo de Sevilla el 9 de julio de 1459 muestra que sus autoridades temían lo peor, tanto para los portugueses como para ellos mismos: a esas alturas nadie ponia en duda que la supervivencia de Ceuta dependía en buena medida del auxilio que le prestaban las villas andaluzas ribereñas del Estrecho.

La seguridad de Tarifa quedó garantizada a partir de agosto de 1462, fecha en la que unas huestes concejiles y nobiliarias al mando de D. Juan de Guzmán, duque de Medina Sidonia, se apoderaban de Gibraltar. La pérdida del Peñón causó consternación en los círculos ilustrados del Magreb, según cuenta el viajero egipcio 'Abd al-Basít, que recorrió buena parte del occidente islámico entre 1462 y 1466. Estaba en Túnez cuando supo la nueva y en su rihla, o relación de viaje, ofrece una versión de lo sucedido que coincide con lo que dicen las crónicas castellanas, pero, curiosamente, atribuye a los portugueses la toma de la plaza. El cronista Zurara refiere que entre los conquistadores se encontraba $D$. Duarte de Meneses, capitán de Alcazarseguer, el cual participó en las negociaciones para la entrega de Gibraltar e intervino luego ante el duque de Medina Sidonia para que se 
guardara el seguro prometido a los musulmanes. Él mismo se encargaría de poner a salvo en Marbella a unos notables gibraltareños y a sus familias, que luego darian "grande fama" - escribe el cronista - "de suas vertudes e bondades na casa de Graada".Es posible que éste sea el motivo de la equivocación cometida por el viajero, la cual habría regocijado sin duda al infante don Enrique, muerto en 1460. Por lo demás, la victoria castellana en Gibraltar hará que Alfonso V intente de nuevo conquistar de nuevo Tánger, contra la cual lanzó tres ataques entre noviembre de 1463 y abril del año siguiente, sin éxito alguno.

Vitorino Magalhães-Godinho ha escrito que a fines de 1465 «una esquadra e un exercito portugueses cercam Málaga por terra e por mar e so o mau tempo impede a tomada da cidade-porto". Este historiador ha sido el primero en preconizar que la monarquía lusitana estuvo interesada por la expansión en el Mediterráneo durante el Cuatrocientos. En esa línea, Luis Adão da Fonseca sostendría posteriormente que el ataque a Málaga en 1465 no hacía sino llevar a la práctica el «programa" expuesto por el infante don Enrique, años antes, en su famoso dictamen. Me temo, sin embargo, que ambos historiadores han confundido un simple asalto corsario con un ataque en toda regla al malinterpretar el testimonio de 'Abd al-Basit, que estaba en la ciudad por aquellas fechas. Cuenta el viajero egipcio que el 17 de diciembre de 1465 los francos portugueses secuestraron a varios vecinos que trabajaban en unos molinos de las afueras de Málaga; cinco días después, un viento huracanado dispersó a los navios lusitanos que andaban en las cercanías.

El episodio tiene todas las trazas de ser una terraçania, o desembarco de corsarios, similar a otras que venian haciendo los marinos portugueses en las costas granadinas y marroquíes. Así pues, no estamos ante un intento fallido de ganar Málaga para convertir en realidad un supuesto sueño del infante don Enrique. Si éste ganó simbólicamente alguna batalla después de muerto, fue la de Gibraltar y no la de Málaga.

La descomposición del estado benimerín como resultado del cambio dinástico acaecido en Fez, en 1465, fue aprovechada por los portugueses para reanudar la expansión en Marruecos. Después del saqueo de Anfa, en 1471 el rey Alfonso tomaba por asalto la plaza de Arcila y, seguidamente, ocupaba la ciudad de Tánger, que había sido evacuada por sus habitantes. Muchos andaluces combatieron al lado de los portugueses en estas campañas, mientras que los granadinos apenas se dejaron ver en el bando contrario. Una ausencia que se explica por la pérdida de Gibraltar y, sobre todo, por la delicada situación interna por la que atravesaba el emirato en ese momento.

\section{$1474-1492$}

Los nobles andaluces que solían colaborar con las autoridades de los presidios africanos, se alinean con Alfonso $V$ al comenzar la guerra de Sucesión castella- 
na(1474-1479). Es el caso de Gonzalo de Saavedra, que se encargará de la subversión en Andalucía hasta su muerte, en el verano de 1475. En cambio, el linaje de los Guzmanes, siempre receloso de los portugueses, abrazaba la causa isabelina. De este modo se puso a prueba la red de solidaridades que unía a los cristianos de una y otra orilla del estrecho de Gibraltar.

En mayo de 1476 un "moro santo" atacaba a Ceuta con su gente y conseguía entrar en la parte despoblada de la ciudad; pero el auxilio enviado por Sevilla-a pesar del estado de guerra existente entre Castilla y Portugal-restableció la situación. Este socorro puso de manifiesto la debilidad de la plaza y, aquel verano, don Enrique de Guzmán cruzaba el Estrecho con cinco mil hombres para tomar Ceuta, llegando a ocupar parte del recinto urbano tras la primera embestida. Pero opta por retirarse al saber que venía el rey de Portugal con refuerzos para los sitiados. La versión portuguesa de lo sucedido es bien diferente: don Alfonso llega a Ceuta en agosto de 1476, cuando la ciudad acababa de sufrir un asedio conjunto "de castelhanos pella Almina, e dos Mouros pella Aljazira(...)». El soberano portugués iba al frente de una gruesa armada con la que proseguirá viaje hasta Marsella, en busca de una alianza con Luis XI de Francia. Un viaje disparatado que el rey Fernando se tomó en serio: la presencia de una escuadra lusa en aguas mediterráneas podía trastocar las relaciones entre Castilla y Granada en unos momentos difíciles para la primera. Por eso ordenó a su flota que persiguiera al adversario lusitano "fasta lo aver o a lo menos la dicha armada", según leemos en un documento sevillano.

Aquel otoño, las autoridades de los presidios urdieron una conspiración con Fernán Arias de Saavedra, hijo de Gonzalo de Saavedra y dueño de Tarifa. Se trataba de desestabilizar al emirato granadino y, por contagio, la banda fronteriza andaluza, utilizando a dos caudillos Abencerrajes exiliados en Marruecos, supervivientes de la última persecución nazarí contra este famoso linaje de la jassa, o élite, granadina. Se les llama a Tarifa con idea de que siembren la discordia entre los alcaides y notables de la serranía de Ronda, muchos de los cuales eran antiguos simpatizantes del bando Abencerraje. Pero el proyecto se va al traste al ser apresado uno de los caudillos por el alcaide de Gibraltar en las proximidades de la frontera.

En 1477 Fernán Arias se enfrentaba abiertamente a los partidarios de la reina Isabel, confiando en el apoyo de las guarniciones portuguesas de Arcila, Tánger, Alcazarseguer y Ceuta, con las cuales mantenían relaciones estrechas los de Tarifa. Pero, al no recibir ayuda, en marzo de 1478 comenzó a provocar a los granadinos en la frontera para que rompieran las treguas. Cuenta Alonso de Palencia-siempre hostil a los portugueses - que esos intentos desestabilizadores coincidieron con la estancia en Granada de una legación lusitana que, según el cronista, pretendia negociar con el emir una alianza contra Castilla. En cualquier caso, Fernando e Isabel mantuvieron una flotilla vigilando las aguas del Estrecho hasta el fin del conflicto. 
La guerra de Sucesión generó resentimiento en un sector de la nobleza portuguesa, que quiso ayudar a los musulmanes cuando los Reyes Católicos iniciaron la conquista del reino de Granada. Al menos, ese fue el pretexto aducido por Juan II (1482-1492), nuevo rey de Portugal, para deshacerse más adelante de los cabecillas de ese grupo nobiliario que, casualmente, se oponian a su política de fortalecimiento del poder monárquico. La verdad es que no hubo ningún intento lusitano de socorrer a los nazaries en su última confrontación con Castilla. Como tampoco lo hubo de participar en la contienda del lado castellano: aparte de los mercenarios, y algún que otro voluntario, en la conquista del reino de Granada sólo estuvieron presentes ciertos nobles exiliados con sus respectivos séquitos. Caso, por ejemplo, de don Álvaro de Portugal, que en el sitio de Málaga(1487) estuvo a punto de morir asesinado por un "moro santo" que lo confundió con el rey Fernando ?

\section{CONCLUSIONES}

Castilla temió que Granada le propinara una "puñalada por la espalda» cada vez que se enfrentó a Portugal a lo largo del período aquí estudiado. Pero, si exceptuamos el tratado de 1369 , no hay datos suficientes que justifiquen esos temores.

La monarquia portuguesa quiso participar en la conquista del emirato granadino en un plano de igualdad con Castilla, sobre todo a raíz de la toma de Ceuta. Pero Juan II rechazó casi siempre las ofertas recibidas en ese sentido porque desconfiaba de las intenciones de sus vecinos. Mención aparte merece la figura del infante don Enrique, el único miembro de la casa de Avis que puso en tela de juicio los "derechos" castellanos sobre Granada.

El emir Muhammad IX el Izquierdo hizo de la recuperación de Ceuta, por la fuerza o por vía diplomática, una de las claves de su política exterior. Los granadinos mostraron también su solidaridad con los norteafricanos cuando éstos fueron atacados por los portugueses en 1437 y 1458 . Más fuertes fueron, sin embargo, los lazos establecidos entre los cristianos de Andalucía y las guarniciones de las fronteiras, o presidios, portugueses del extremo occidental del Magreb.

Sobre los refugiados politicos que se establecieron en territorio granadino después de la conquista, véase LOPEz DE COCA CASTANER, J. E.: "Exiliados portugueses en Málaga a fines de la Edad Media", Liv. ro de Homenagem ao Profesor Doutor Humberto Carlos Baquero Moreno, II(Oporto, 2003), pp.667-670. 